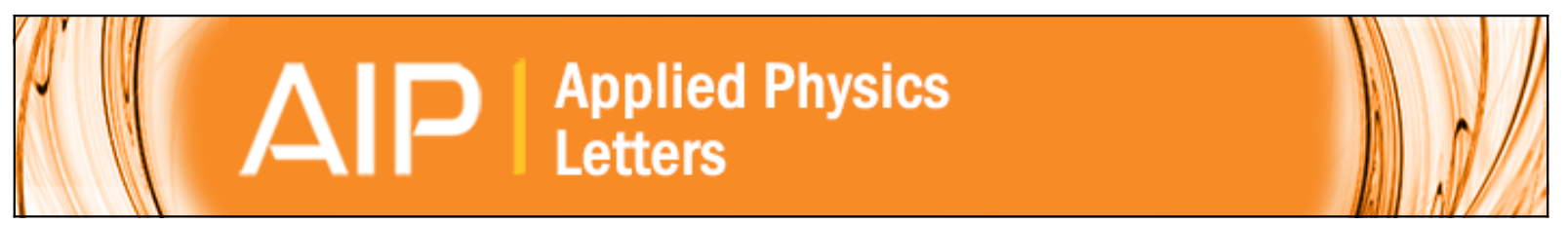

\title{
Low dark current and high speed ZnO metal-semiconductor-metal photodetector on SiO2/Si substrate
}

Deniz Çalışkan, Bayram Bütün, M. Cihan Çakır, Şadan Özcan, and Ekmel Özbay

Citation: Applied Physics Letters 105, 161108 (2014); doi: 10.1063/1.4899297

View online: http://dx.doi.org/10.1063/1.4899297

View Table of Contents: http://scitation.aip.org/content/aip/journal/apl/105/16?ver=pdfcov

Published by the AIP Publishing

\section{Articles you may be interested in}

Metal-semiconductor-metal photodetector on as-deposited TiO2 thin films on sapphire substrate

J. Vac. Sci. Technol. B 31, 020606 (2013); 10.1116/1.4794526

Effects of annealing temperature on the characteristics of Ga-doped $\mathrm{ZnO}$ film metal-semiconductor-metal ultraviolet photodetectors

J. Appl. Phys. 113, 084501 (2013); 10.1063/1.4791760

MgZnO-based metal-semiconductor-metal solar-blind photodetectors on $\mathrm{ZnO}$ substrates

Appl. Phys. Lett. 98, 221112 (2011); 10.1063/1.3596479

Electrical breakdown of $\mathrm{ZnO}$ nanowires in metal-semiconductor-metal structure

Appl. Phys. Lett. 96, 253112 (2010); 10.1063/1.3457169

Effect of high-energy electron beam irradiation on the properties of $\mathrm{ZnO}$ thin films prepared by magnetron sputtering

J. Appl. Phys. 105, 123509 (2009); 10.1063/1.3149783

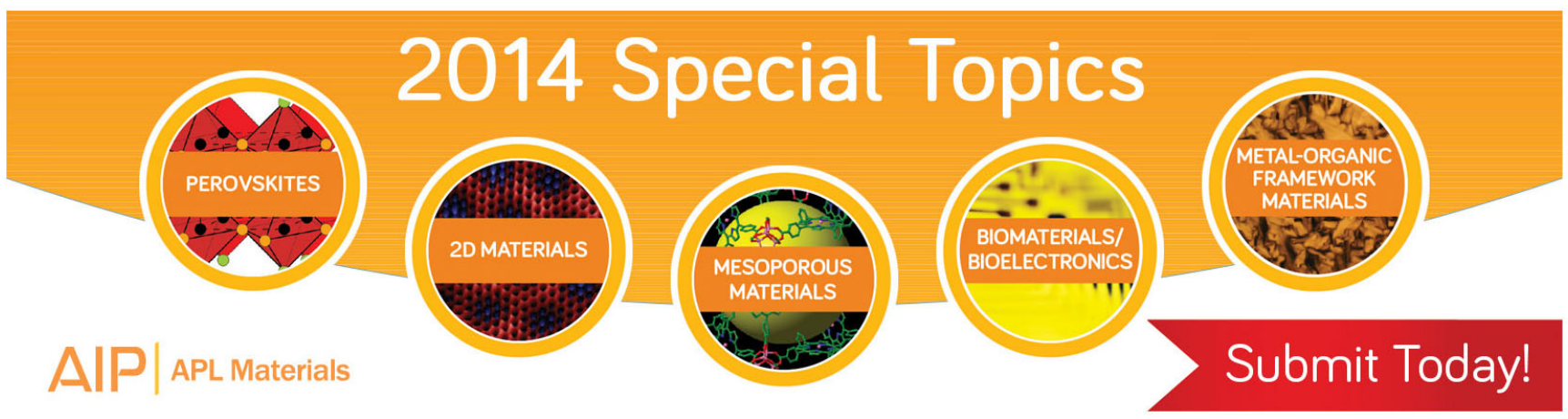




\title{
Low dark current and high speed $\mathrm{ZnO}$ metal-semiconductor-metal photodetector on $\mathrm{SiO}_{2} / \mathrm{Si}$ substrate
}

\author{
Deniz Çalışkan, ${ }^{1,2, a)}$ Bayram Bütün, ${ }^{1}$ M. Cihan Çakır, ${ }^{1}$ Şadan Özcan, ${ }^{3}$ and Ekmel Özbay ${ }^{1,4}$ \\ ${ }^{1}$ Nanotechnology Research Center, Bilkent University, 06800 Bilkent, Ankara, Turkey \\ ${ }^{2}$ Department of Nanotechnology and Nanomedicine, Hacettepe University, 06800 Beytepe, Ankara, Turkey \\ ${ }^{3}$ Department of Physics Engineering, Hacettepe University, 06800 Beytepe, Ankara, Turkey \\ ${ }^{4}$ Department of Electrical and Electronics Engineering and Department of Physics, Bilkent University, \\ 06800 Bilkent, Ankara, Turkey
}

(Received 17 July 2014; accepted 11 October 2014; published online 21 October 2014)

$\mathrm{ZnO}$ thin films are deposited by radio-frequency magnetron sputtering on thermally grown $\mathrm{SiO}_{2}$ on Si substrates. Pt/Au contacts are fabricated by standard photolithography and lift-off in order to form a metal-semiconductor-metal (MSM) photodetector. The dark current of the photodetector is measured as $1 \mathrm{pA}$ at $100 \mathrm{~V}$ bias, corresponding to $100 \mathrm{pA} / \mathrm{cm}^{2}$ current density. Spectral photoresponse measurement showed the usual spectral behavior and $0.35 \mathrm{~A} / \mathrm{W}$ responsivity at a $100 \mathrm{~V}$ bias. The rise and fall times for the photocurrent are measured as $22 \mathrm{ps}$ and $8 \mathrm{~ns}$, respectively, which are the lowest values to date. Scanning electron microscope image shows high aspect ratio and dense grains indicating high surface area. Low dark current density and high speed response are attributed to high number of recombination centers due to film morphology, deducing from photoluminescence measurements. These results show that as deposited $\mathrm{ZnO}$ thin film MSM photodetectors can be used for the applications needed for low light level detection and fast operation. (C) 2014 AIP Publishing LLC. [http://dx.doi.org/10.1063/1.4899297]

Low dark current and high speed metal oxide ultraviolet (UV) photodetectors are of interest due to their potential use in civil applications such as air quality monitoring, gas detection, and flame detection and military applications such as UV communications and missile warning. ${ }^{1} \mathrm{ZnO}$ is an alternative material to the widely known GaN based material system that is used for these applications ${ }^{2,3}$ because of simpler growth technology and comparable device performance. ${ }^{4}$ Recently, $\mathrm{ZnO}$ based low dark current photodetectors have been fabricated by metal-organic chemical vapor deposition grown films, ${ }^{5}$ atomic layer deposition, ${ }^{6}$ ball milled nanoparticles, ${ }^{7}$ radio-frequency (RF) magnetron sputtering, ${ }^{8}$ and other various methods. Although dark currents for the devices are reported in the $10^{-9}-10^{-12} \mathrm{~A}$ range, calculated dark current densities are in the order of $\mathrm{nA} / \mathrm{cm}^{2}$ or even higher. For high performance UV detection, much lower current densities are required.

Another important performance criterion for photodetectors is the time response of the device. Fast time response $\mathrm{ZnO}$ photodetectors were published recently, but all of these works report rise times in $\sim 10^{-9} \mathrm{~s}$ scales, although they are fabricated on good quality thin films. ${ }^{9-11}$ In this work, we present very low dark current density and very high speed UV photodetectors fabricated with reactively RF magnetron sputtered $\mathrm{ZnO}$ thin films on $\mathrm{SiO}_{2} / \mathrm{Si}$ substrates.

Prior to the deposition of $\mathrm{ZnO}$ thin film, Si wafer was cleaned using the standard RCA recipe and then wet oxidized at $1100^{\circ} \mathrm{C}$ to achieve $750 \mathrm{~nm}$ thick $\mathrm{SiO}_{2}$ film on $\mathrm{Si}$ substrate. After dicing $10 \mathrm{~mm} \times 10 \mathrm{~mm}$ pieces, the substrates were cleaned in acetone and isopropanol in ultrasonic bath, rinsed in running deionized (DI) water and dried by nitrogen.

\footnotetext{
${ }^{\text {a) }}$ Author to whom correspondence should be addressed. Electronic mail: dcaliskan@fen.bilkent.edu.tr
}

After 5 min of dehydration on a hotplate at $120^{\circ} \mathrm{C}$, the substrates were directly loaded to the Nanovak NVTS-400 combo PVD system. After achieving a $2.5 \times 10^{-6}$ mbar vacuum level, $\mathrm{O}_{2}$ and $\mathrm{Ar}$ gases were introduced to the system, both with partial pressures of 24/100, respectively. After sputter-cleaning the target for $10 \mathrm{~min}, 150 \mathrm{~nm}$ of $\mathrm{ZnO}$ thin film was deposited on the substrate at 1.85 mbar pressure, $80 \mathrm{~W}$ RF power, and a $0.5 \AA / \mathrm{s}$ deposition rate without intentional heating or cooling. No post annealing of films were applied. Scanning electron microscope (SEM) image of the grown film is shown in Fig. 1, indicating that the film was grown in island-growth mode as very dense and random, vertically aligned high aspect ratio grains, or nanowire-like structures. This type of growth leads to very high surfacearea/volume ratio through the film.

Contacts with $2 \mu \mathrm{m}$ width and $10 \mu \mathrm{m}$ spacing were photolithographically defined on the substrate. $\mathrm{Pt}$ is selected as Schottky contact on deposited $\mathrm{ZnO}$, due to its high work function to obtain higher Schottky barrier and lower leakage

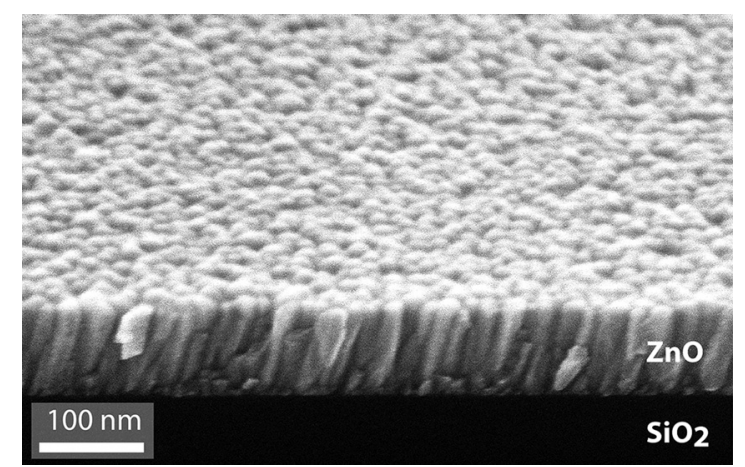

FIG. 1. SEM image of the grown $\mathrm{ZnO}$ thin film on $\mathrm{SiO}_{2}$. 


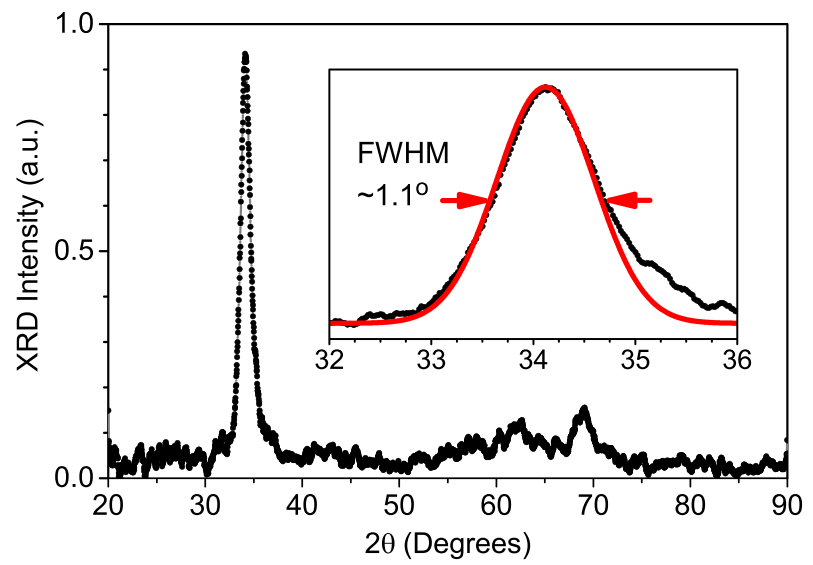

FIG. 2. XRD pattern obtained from the sample. (Inset) Gaussian fit and FWHM of the fit.

current. After deposition of Pt/Au (100 ̊/1000 ̊) using a Leybold Univex-350 e-beam evaporator, lift off was applied. $^{12}$ The total device active area was $100 \mu \mathrm{m} \times$ $100 \mu \mathrm{m}$.

X-ray diffraction (XRD) measurements were performed using a Rigaku powder diffractometer, and photoluminescence (PL) measurement was performed on a Horiba Jobin Yvon system. Current-voltage (IV) was performed with an Agilent B1500A semiconductor parameter analyzer, and the spectral photoresponse was measured using Spectral Products DK240 monochromator and Keithley SMU. Speed measurements were done by using a $266 \mathrm{~nm}$ Fianium fiber laser with a 10 ps pulse width and an Agilent $50 \mathrm{GHz}$ oscilloscope.

XRD for structural analysis of the grown film is performed and result is shown in Fig. 2. The peak at $34.1^{\circ}$ is (002) peak of $\mathrm{ZnO}$. In the inset of Fig. 2, the Gaussian fit to (002) peak and full width at half maximum (FWHM) of the fit is shown. FWHM of the (002) peak is measured to be $1.1^{\circ}$ and Scherrer equation gives approx. $7.4 \mathrm{~nm}$ of average crystallite size.

The PL measurement result is shown in Fig. 3. The band-gap excitation (BGE) peak is observed at $3.18 \mathrm{eV} . \mathrm{O}_{2}$ or $\mathrm{Zn}$ vacancies are responsible for the short peak observed at $2.5 \mathrm{eV}{ }^{4}$ Reactive deposition of the film results in a decrease at the intensity of this peak. The wide peak that is observed at $1.67 \mathrm{eV}$ is associated with recombination centers

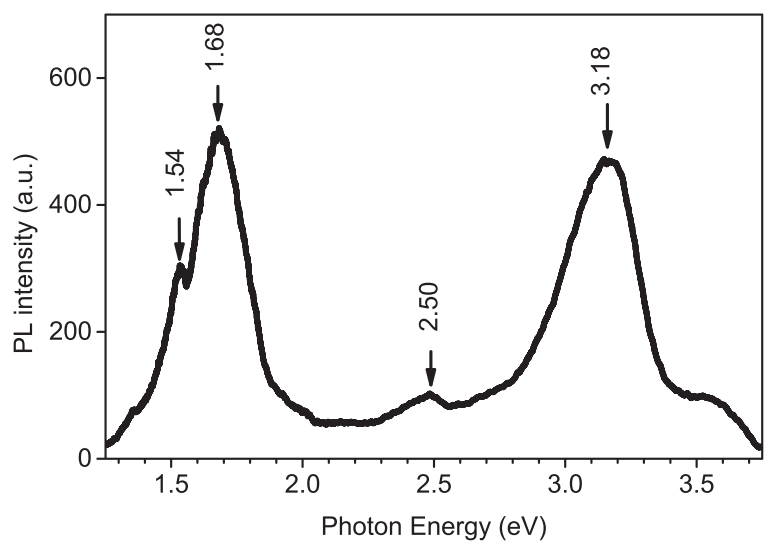

FIG. 3. PL graph for $\mathrm{ZnO}$ thin film.

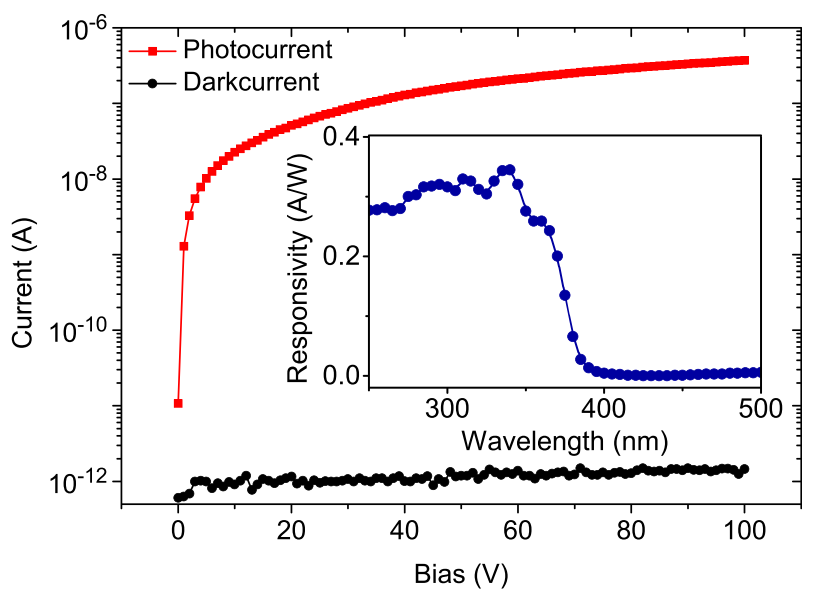

FIG. 4. Dark and photo IV of the fabricated MSM photodiodes. (Inset) Spectral responsivity.

present in the $\mathrm{ZnO}$ crystal lattice, also originating through native defects. ${ }^{13}$ Surface band bending is a generally accepted the reason for the $1.54 \mathrm{eV}$ peak in PL data. ${ }^{14}$ The nanowire like structure that is seen in the SEM image in Fig. 1 shows that the surface area of the grain boundaries is high. Due to this large surface area, it is expected that a surface band bending effect will be observed with the film that is validated with the $1.54 \mathrm{eV}$ peak observed in the PL data.

Fig. 4 shows the dark current and photo current measurement results that were performed under illumination of a $330 \mathrm{~nm}$ wavelength and $984 \mathrm{nW}$ optical power. Up to a $100 \mathrm{~V}$ bias, no breakdown is observed. As can be seen in the inset of Fig. 4, the spectral response measurement gives the peak responsivity of $0.35 \mathrm{~A} / \mathrm{W}$ at $340 \mathrm{~nm}$.

The rejection ratio between $340 \mathrm{~nm}$ and $450 \mathrm{~nm}$ was measured more than 300 for the device. Dark current measured from the device at a $100 \mathrm{~V}$ bias voltage was only $1 \mathrm{pA}$, which is limited with the measurement setup. This dark current corresponds to a $100 \mathrm{pA} / \mathrm{cm}^{2}$ current density, which is the lowest value to date. Low photocurrent, with respect to the values in the literature, can be attributed to the lack of photoconductive gain due to high contact spacing and high number of recombination centers at the boundaries of the grains.

The time response measured from the device is shown in Fig. 5. Rise time (10\%-90\%) is measured as 22 ps. The

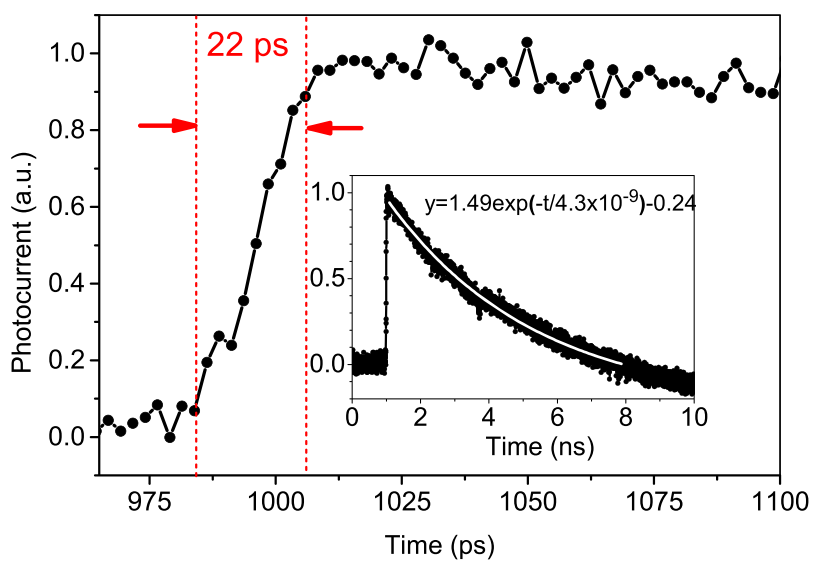

FIG. 5. Rise time of the device. (Inset) Time response in nanosecond scale. 
fall time for the device was $8 \mathrm{~ns}$, which fits to the exponential decay perfectly, showing that only one component exists in the time response. Rise times found in the literature for high speed $\mathrm{ZnO}$ based photodetectors are in nanoseconds. ${ }^{9}, 10,15-17$ The surface band bending related peak observed in PL measurement and the vertically aligned grown $\mathrm{ZnO}$ nanorods, observed in SEM inspection, indicating high surface area, therefore high trap density, seem to be responsible for very fast recombination of photogenerated carriers, resulting low photoresponse but very fast time response.

In conclusion, $\mathrm{Pt} / \mathrm{Au}$ contact metal-semiconductor-metal (MSM) photodetectors were fabricated on $\mathrm{ZnO}$ thin films grown on $\mathrm{SiO}_{2} / \mathrm{Si}$ substrates by reactive RF magnetron sputtering. A very low dark current density of $100 \mathrm{pA} / \mathrm{cm}^{2}$ at a $100 \mathrm{~V}$ bias voltage was achieved. $0.35 \mathrm{~A} / \mathrm{W}$ responsivity at a $340 \mathrm{~nm}$ wavelength and rejection ratio of more than 300 between $340 \mathrm{~nm}$ and $450 \mathrm{~nm}$ was measured from the device. The very fast response of $22 \mathrm{ps}$ of the rise time and $8 \mathrm{~ns}$ of the fall time were measured from the device. Low dark current density and high speed response at a cost of responsivity can be attributed to high number of recombination centers due to high surface area due to high aspect ratio and dense grains. These results show that low dark current densities and a fast time response can be achieved from a simple processing of the deposited $\mathrm{ZnO}$ films with a carefully adjusted deposition process.

This work was supported by the projects DPT-HAMIT, DPT-FOTON, NATO-SET-193, and TUBITAK under Project Nos. 113E331, 109A015, and 109E301, respectively.
One of the authors (E.O.) also acknowledges partial support from the Turkish Academy of Sciences. We would like to thank Dr. Abdullah Ceylan for the XRD measurements and Pakize Oztop for the PL measurements.

${ }^{1}$ M. Razeghi and A. Rogalski, J. Appl. Phys. 79, 7433 (1996).

${ }^{2}$ M. Gökkavas, S. Butun, T. Tut, N. Biyikli, and E. Ozbay, Photonics Nanostruct. Fundam. Appl. 5, 53 (2007).

${ }^{3}$ S. Butun, M. Gökkavas, H. Yu, and E. Ozbay, Appl. Phys. Lett. 89, 073503 (2006).

${ }^{4} \ddot{U}$. Özgür, Ya. I. Alivov, C. Liu, A. Teke, and M. A. Reshchikov, J. Appl. Phys. 98, 041301 (2005).

${ }^{5}$ Y. Liu, C. R. Gorla, S. Liang, N. Emanetoglu, Y. Lu, H. Shen, and M. Wraback, J. Electron. Mater. 29, 69 (2000).

${ }^{6}$ P. Hazra, S. K. Singh, and S. Jit, J. Semicond. Technol. Sci. 14, 117 (2014).

${ }^{7}$ S. P. Chang and K. J. Chen, J. Nanomater. 2012, 602398.

${ }^{8}$ M. Liu and H. K. Kim, Appl. Phys. Lett. 84, 173 (2004).

${ }^{9}$ K. W. Liu, J. G. Ma, J. Y. Zhang, Y. M. Lu, D. Y. Jiang, B. H. Li, D. X. Zhao, Z. Z. Zhang, B. Yao, and D. Z. Shen, Solid State Electron. 51, 757 (2007).

${ }^{10}$ J. Sun, F. J. Liu, H. Q. Huang, J. W. Zhao, Z. F. Hu, X. Q. Zhang, and Y. S. Wang, Appl. Surf. Sci. 257, 921 (2010).

${ }^{11}$ Z. Bi, X. Yang, J. Zhang, X. Bian, D. Wang, X. Zhang, and X. Hou, J. Electron. Mater. 38, 609 (2009).

${ }^{12}$ D. Caliskan, B. Butun, S. Ozcan, and E. Ozbay, J. Vac. Sci. Technol. B 31, 020606 (2013).

${ }^{13}$ T. Minami, H. Nanto, and S. Takata, J. Lumin. 24/25, 63 (1981).

${ }^{14}$ J. C. Moore and C. V. Thompson, Sensors 13, 9921 (2013).

${ }^{15}$ S. Liang, H. Sheng, Y. Liu, Z. Huo, Y. Lu, and H. Shen, J. Cryst. Growth 225, 110 (2001).

${ }^{16}$ D. Jiang, J. Zhang, Y. Lu, K. Liu, D. Zhao, Z. Zhang, D. Shen, and X. Fan, Solid State Electron. 52, 679 (2008).

${ }^{17}$ Q. A. Xu, J. W. Zhang, K. R. Ju, X. D. Yang, and X. Hou, J. Cryst. Growth 289, 44 (2006). 